\title{
Engaging Students in Learning: Lessons from Short-Term Study Abroad Experiences in Italy
}

\author{
By Susan H. Peet ${ }^{*}$ \\ Deborah Wooldridge ${ }^{\dagger}$ \\ Michael Sturm
}

Study abroad is being promoted as a strategy to enhance undergraduate students' intercultural knowledge and competence and life-long learning. This study reports on students' knowledge, skills and dispositions that occur as a result of participating in a short-term study abroad experience in Italy. Students provided responses to open-ended prompts and five structured questions. Findings of the study suggest students gain valuable insight while participating in hands-on, structured, study abroad experiences

\section{Introduction}

The late Professor of Education Dr. Cesare Scurati of the Catholic University in Milan sat in a warm, Italian classroom facing a handful of young students from the United States. After an engaging conversation about the differences in the Italian system of education and the educational system in the U.S., a question was posed by someone from the United States, "Why should students from the U.S. spend time and money to come to Italy to observe and learn from your schools and culture?" The question continued, "After all, we are not likely to live or teach in an Italian system. So, what is the point of us coming here to learn? Is it worth it?" The purpose of this paper is to address this central question. The paper provides substantial evidence to document Professor Scurati's conclusion that it is worth the time and money to participate in short-term study abroad experiences (Personal Communication, May 17, 2009).

\section{Literature Review}

Perry, Stone, and Tarrant (2013) document the growth in study abroad experiences over the past decade citing growth from 75,000 in 1990 to 270,000 in 2012. The fastest growing segment of the study abroad experiences has been

\footnotetext{
*Senior Lecturer, Bowling Green State University, USA.

†Professor\& Director, Bowling Green State University, USA.

${ }^{*}$ Instructor, Bowling Green State University, USA.
} 
short-term study abroad programs. Additionally, the scholarship and theoretical understanding surrounding the benefits of study abroad experiences have advanced considerably (Tarrant, 2010). Over the past decade study abroad experiences are increasingly viewed as an important vehicle to facilitate the global awareness and citizenry of students who are born and educated in the United States (Stearns, 2009).

Scholars have written about the benefits of studying the Italian Early Care and Education system (New, 2001) to enhance an understanding of the social and economic value of children in society. Political, social and cultural similarities and differences of the role of childhood in the Italian system and the role of childhood in the U.S. has been written about extensively. Although the Italian system is not without challenges, it is widely viewed as an exemplary system where the importance of children's wellbeing and education is highly valued.

Preparing the next generation of teachers must include a focus on issues of globalization. Globalization is an omnipresent force in our society today and it is here to stay. The evolution of western dance music offers an excellent example of the historical impact of globalization and it illustrates the pace of globalization from the 1800 s to today. The following link shows how as time and technology progress has the spread of western dance music. http://www. thomson.co.uk/blog/wp-content/uploads/infographic/interactive-music-map/in dex.html.

Globalization has transformed society and politics and is changing demographics around the world. These changes affect schools and communities, and those who provide leadership must understand diversity, inclusion, and globalization (Friedman, 2006). Thus, a global society symbolizes a new way of thinking about diversity and inclusion efforts (Banks, 2008; Banks \& Banks, 2004). A long-term study conducted by Malewski, Sharma, and Phillion (2012) found that providing students with an international experience gave students the theoretical understandings and practical applications for teaching culturally diverse students. These experiences were found to assist pre-service teachers in asking critical questions, reflecting on teaching, and increasing abilities to work in culturally diverse classrooms. Professionals must design environments for learning which take into account diversity, inclusion, and globalization. School environments are charged with socializing children, preparing students for the larger global environment, and collaborating with parents, community members, and teachers (Banks, 2006; Gay, 2002). Thus, study abroad programs for early childhood education majors can enhance undergraduate education and facilitate their ability to meet the diversity that exists in schools.

The mission of Bowling Green State University and the College of Education and Human Development is to support educational experiences inside and outside the classroom that enhance the lives of students, faculty and staff. Students are prepared for lifelong career growth, lives of engaged citizenship and leadership in a global society. Within our learning community, we build a welcoming, safe, and diverse environment where the creative ideas 
and achievements of all can benefit others throughout Ohio, the nation and the world (Bowling Green State University, 2013 ${ }^{\mathrm{a}}$ ).

Bowling Green State University has established educational priorities for students who study abroad. Study Abroad experiences are intended to assist students with gaining competence in intercultural knowledge and competence and life-long learning. Intercultural knowledge and competence is a set of cognitive, affective, and behavioral skills and characteristics that support effective and appropriate interaction in a variety of cultural contexts. Intercultural Knowledge and Competence contains six basic domains. The domains include cultural self-awareness, knowledge of cultural worldview frameworks, empathy, verbal and non-verbal communication, curiosity and openness to communicate with people from diverse backgrounds. Life-long learning is a purposeful learning activity, undertaken on an ongoing basis with the aim of improving knowledge, skills, and competence. Life-long learning goals are designed to increase students' curiosity for understanding a topic in more detail, initiative to complete work, independence in gaining unique information, transfer previous learning, reflection on prior learning.

This paper documents some of the ways that students learned and grew in intercultural knowledge and competence and life-long learning as a result of participaing in a short-term study abroad experience. The specific research questions are: What are the benefits of study abroad experiences for undergraduate student? How does study abroad impact undergraduate students?

\section{Method}

\section{Context for Studying in Italy}

Bowling Green State University along with the School of Family and Consumer Science has supported a total of five study abroad trips to Italy as a strategy to expand opportunities for students to study abroad. These programs have provided opportunities for approximately 60 students to enhance their intercultural knowledge and competence and establish a foundation for lifelong learning. The data for this paper was collected during the Summer 2013 offering of Educational and Cultural Explorations in Italy and is based on seven students. Educational and Cultural Explorations in Italy is a university course that includes a course syllabus, assigned readings and assignments and travel abroad. The course focuses on helping students gain a fuller understanding of the educational systems in Italy for early childhood education. See Appendix A for a brief description of the schools that were visited and quotes from students about the sites. The course also provides opportunities for students to visit cultural and historical sites of interest in Venice, Florence (Pisa, Cinque Terra, Uffuzi Museum, Accademia), Rome (Vatican and Colosseum) and Sorrento (Amalfi Coast), Italy.

Pre-departure preparation is critical to increasing student learning experiences. Preparing students for the cultural, economic, and educational 
experiences they will have is linked with increased student outcomes. Students who participated in the class met monthly for 5 months before traveling to Italy. In these meetings, the itinerary and expectations for the trip were reviewed, and students' questions were answered.

Targeted readings, podcasts and websites were provided to students during the trip. The instructional design of the course included students' access to targeted learning materials, which were specifically selected to facilitate an understanding of the school, site or experience that was to take place.

Blog and journal data collection are qualitative research tools used for the purpose of understanding a phenomenon or experience (Creswell, 2008). A qualitative analysis of the blogs and journal entries provides a more authentic insight into the students' perceptions of growth and perceptions surrounding intercultural knowledge and competence, and life-long learning.

Structured reflection was also an important part of the class. Guided reflection, discussion, and conversation as well as daily and weekly reflection diaries were an integral part of the short-term study abroad experience. Students were required to participate in multiple opportunities for reflection. The evening meal together was used as an opportunity for reflection and debriefing about the day's experiences. Each person was included in reflection discussion to enhance his/her understanding of the sites of the day. Additionally, each student was required to post comments on a blog and/or in a written diary to enhance the students' reflection. These avenues of reflection enhanced the learning experiences for the pre-teacher candidates.

\section{Methodology}

The data reported in this paper is part of a larger research project that collected data from multiple sources including pre-departure questionnaires, post-return questionnaires, daily blogs, daily reflections, and end of the trip reflections. Findings related to overall influence of the study abroad experience have been reported elsewhere (Wooldridge, Peet and Sturm, 2013). This paper reports an in-depth look at students' perceptions (and usually their own words) of their changes in global learning and awareness as a result of visiting Italy.

\section{Subjects}

The seven students who participated in Cultural Explorations in Italy 2013 participated in this study. The students are all undergraduate students (4 juniors and 3 seniors) at Bowling Green State University. The students were majoring in Early Childhood Education, Human Development and Family Studies, Intervention Services and Adolescent Young Adult Social Studies. One student has previously visited Italy while the other six students had not traveled to Italy. Students reported their reason to participate in this class as the opportunity to gain global experience (6 students), enhance global awareness (4 students), enhance global knowledge (6 students), and to earn college credit (6). Six students identified themselves as European-American, while one 
student identified herself as Black or African-American. Students completed informed consent documents so they were fully informed that they were participating in a research project.

\section{Measures}

There are two primary sources of data for this study. First, students' responded to five questions about how they view themselves compared to others their own age in terms of knowledge, skills and dispositions on dimensions of global learning. Students were asked to rank from 1 (major weakness) to 5 (major strength) their perceptions of knowledge, skill and disposition related to:

1. Communication skills in settings where English is not the primary language spoken. (skill question)

2. Knowledge of one's (my) own culture (knowledge question)

3. Knowledge about the cultural background of others (knowledge question)

4. Openness to having my views challenged (dispositions question)

5. Ability to see the world from someone else's perspective. (dispositions question)

Second, the students in this study were allotted time to reflect on their experiences each day. Reflection allowed the students to understand how these experiences contributed to their growth as individuals as well as future classroom teachers. The group leaders suggested that the students reflect on their learning experiences and how they were adjusting to a new culture. By keeping the structure of the blogging open and relaxed, the students were free to provide authentic answers and reflections. Students' journals, blogs, and daily reflections were used to identify major themes surrounding student perceptions of the knowledge, skills and dispositions associated with studying abroad. The journal entries were completed by using a workbook that was provided to students at the beginning of the experiences. The workbook provided background information of the different cultural and historical sites and schools that the students visited. Students were asked to respond to questions about the "best" and "worst" of the day and what they learned from each school or site. Additionally, each student established his or her own blog. A faculty member who is an expert in technology trained and assisted students in blogging. http://cindyrossitaly.wordpress.com/

\section{Results}

\section{Questionnaire Data}

Findings indicated that students' showed a positive increase in knowledge, skill and dispositions. Table 1 includes the actual scores that reflect changes in 
students' perceptions from pre-departure to post-return on five dimensions. The results show that without exception all 7 students reported an increase in global learning for each of the five dimensions. It is worth noting the very low scores most students gave themselves on the dimension prior to the class/trip (average score was .57). Only one student (and the one student who had previously traveled to Italy) ranked herself at a level 3. All others were ranked at a level 0 or 1 before the class/trip. Upon return, all students 6 of the 7 students ranked themselves at a 4 (and one student ranked herself at a 3); the average score for the group was 3.8. Also, every score change was in the positive direction. Five students perceived that they changed 4 points (from 0 to 4 ), one student perceived changing 3 points (from 0 to 3 ), and one student perceived changing by 1 point (from 3 to 4 ). It is noteworthy that on the five point scale, the average for the group moved from .57 to 3.4 .

Table 1. Pre- and Post-Perceptions of Global Learning and Awareness

\begin{tabular}{|c|c|c|c|}
\hline & Pre-Departure & Post-Trip & Change Score \\
\hline Student 1 & 0 & +4 & +4 \\
\hline Student 2 & +1 & +3 & +2 \\
\hline Student 3 & $\mathbf{+ 3}$ & $\mathbf{+ 4}$ & $+\mathbf{1}$ \\
\hline Student 4 & 0 & +4 & +4 \\
\hline Student 5 & 0 & +4 & +4 \\
\hline Student 6 & 0 & +4 & +4 \\
\hline Student 7 & 0 & +4 & +4 \\
\hline $\begin{array}{c}\text { Average } \\
\text { Score }\end{array}$ & +.57 & +3.8 & +3.2 \\
\hline
\end{tabular}

\section{Journals and Blogs}

Students blogged, journaled and reflected on the experiences with schools as well as with experiences visiting historical and cultural sites. These reflections document students' perceptions in the domains of knowledge, skills, and dispositions. Additionally, thematic topics were identified from reviewing the blog/journal entries.

Evidence of enhanced intercultural knowledge and competence in the domains of knowledge, skills and dispositions include the following reflections from students:

- Knowledge: "To begin with, comparing the classrooms I visited in Italy to the classrooms I have been a part of in the U.S. shows a big difference in artistic development. From what I saw in Italy, the lessons gave the children a lot of creative freedom. Although the children were young, I never saw them completing a worksheet. The students in Italy were always doing a hands-onactivity, and they looked interested and engaged the entire time. The experiences I had make the artistic development in Italy seem much greater. From a young age, the children at some Italy schools are writing their own songs and beats, improvising on the 
recorder, and building a strong creative foundation for the rest of their years in school."

- Skills: "After seeing the amount of creativity and beauty coming from these schools, I know that I can incorporate these ideas, activities and teaching strategies into my own classroom. By using art, we can reach those students who have behavioral issues, fine and gross motor disabilities, as well as hearing or seeing disabilities. These schools also combined art with nature, in that a lot of their work had been done outside. This is another tool you can incorporate into your classroom with any subject."

- Dispositions: "Overall I was completely amazed by the pieces of art and architecture seen throughout Italy. The buildings, the sculptures, and the paintings all left lasting impression on me. Being able to see these sights first hand was completely astonishing. My favorite two sights that we saw were Michelangelo's David and The Coliseum. David did not have any significant meaning to me until we stepped inside the Galleria dell'Accademia. I was completely stunned by the detail and the beauty of that statue. I remember just staring at it and circling the gigantic statue just wishing I could have asked Michelangelo a question or two about it!"

Evidence of enhanced perceptions of life-long learning (in the areas of knowledge, skills and dispositions) include the following reflections from students:

- Knowledge: "I was familiar with some different types of school in the U.S., but I did not realize how differently some schools were being run in Italy. Although it may not always be fair to compare schools in the U.S. to schools in other countries, it does seem like there are valuable things to learn. This trip has made me think a lot about the values our country has, as well as my own values. It is very interesting to think about what is truly important for education and the children."

- Skills: "Next, traveling to Italy has given me so many neat ideas for my future classroom in the U.S. In addition to ideas, traveling to Italy has me very interested in traveling to other places to see what the culture has to offer. I love learning new things and this trip showed me how a classroom could be, and I truly value those experiences. This trip has provided me with many ideas for my future classroom. Many of my favorite ideas are from Mamma Mara. Mamma Mara was definitely my favorite school of the trip because of the hominess and community that Paolo and the teachers developed. In my classroom someday, I want to recreate a homey environment, like Mamma Mara developed. I want to be 
sure to have pictures of everyone in the class around the room, to include everyone in creating projects that represent my entire classroom."

- Dispositions: "As a group I feel like we grew a lot, learned a lot, and are coming home with a brand new perceptive on the world and what it means to travel and meet new people."

A review of the students' journal entries and blogs also show some themes around topics of significant learning and awareness. These topics include:

- Perceptions of time: "They seem to value time differently here as they seem to focus more on relationships and people while we (US citizens) are just rushing around."

- Struggles with communication: One student noted in her blog that "I got to haggle with a vendor today".

- Culture of food: Students experienced culture shock with the Italian food culture. While visiting a new culture, food and meals is one dimension that the differences were easily noted. Based on students' blogs, one student commented that the "food was obviously amazing"; another student noted she was "getting used to three course meals, and an additional student indicated that "I did not know how much I would miss ice". Students learned quickly that the culture of food is much different in Italy than it is in the U.S. A significant learning happened for students upon eating a meal at Hard Rock Café in Rome. One student wrote that she "didn't realize how much they missed American food such as burgers and French fries."

- Educational strategies/methods: Students began thinking about how they could apply what they were seeing into their future classrooms. For example, a student said, "The teachers at Mamma Mara used some creative methods that I want to try to incorporate when I have my own classroom." This student's statement expressed that she intends to transfer the knowledge that she gained from the experience and use it for her own teaching. This same student also noted that the teachers in Italy "don't appear to be teaching to the test".

- Summary/Reflective Statements: The students also offered summary statements at the end of the trip that explain what they feel they gained as a result of the class/trip. One student indicated, "I learned so many things about culture and language." Another student said, "I learned so much from being at the schools, trying food, seeing the culture and learning about the history."

The above student reflections support the importance of experiential learning. In this study, a short-term study abroad experience strengthened students' knowledge and dispositions. Furthermore, students' international 
participation enhanced their understanding of globalization. These experiences are likely to help future teachers meet the demands of culturally diverse classrooms. We assert that this study abroad experience exemplifies a best practice in training pre-service teachers.

\section{Conclusions}

Professor Cesare Scurati's comments about the ultimate value of study abroad have been supported by the findings of this study. Significant insights into culture, history, education, and communication can be attained as a result of study abroad in large part because it helps us to understand ourselves. These insights help us to more fully take the perspective of others. The findings of this research project provide clear evidence that students' perceived significant gains in intercultural knowledge and competence as well as establishing a base for life-long learning. Students who participated in this class/trip consistently provided quantitative and qualitative data to demonstrate significant learning happened. The hands-on experience in another country where the language and cultural barriers were significant, led to perceptions of significant growth and insight. Specifically, three conclusions may be drawn from this study:

First, all students reported a perception of gain in global awareness. Even though students may start from different beginning points (i.e., some have more experience with global settings than do others), each of the seven students reported gains. The students who had no previous global experience gained the most.

Second, all students reported a perception of gain in knowledge, skills and dispositions related to intercultural knowledge and competence and life-long learning.

Third, short-term study abroad programs are viable avenues to help students gain an increased understanding of global issues. Colleges and universities are well suited to support this development and learning among college age students. Cultural and educational experiences need to be carefully designed to ensure the dissemination of adequate content information, time for reflection, and opportunities to connect with people who come from diverse backgrounds.

Professor Cesare Scurati's answer to the question, "Why should students from the U.S. spend their time and money to come to Italy to observe and learn?" was simple. He said, "learning about other cultures helps a person to understand his or her own culture more fully. And when you understand your own system more fully, you are more prepared to interact in a diverse world" (Personal Communication, May 17, 2009). The qualitative responses that have been included in this paper support the notion that he was correct; students learn and grow in both intercultural knowledge and competence as well as build on life-long learning as a result of a study abroad experience.

\section{Acknowledgement}


We acknowledge with appreciation the contributions of Zachary Black in the development of this paper

\section{References}

Banks, J.A. (2006). Cultural Diversity and Education: Foundations, Curriculum and Teaching. Boston: Allyn and Bacon.

Banks, J. A. \& Banks, C. M. (2004). Multicultural education: Historical development, dimensions, and practices; Banks, J.A. (Ed). Handbook of Research in Multicultural Education. San Francisco: Jossey-Bass, p. 3- 29.

Banks, J. (2008). An Introduction to Multicultural Education. Boston: Allyn and Bacon.

Bennett, M. J. (2009). Defining, measuring, and facilitating intercultural learning: A conceptual introduction to the Intercultural Education double supplement. Intercultural Education (20) S1-2, S1-13.

Black, Z. (2013). Students' perceptions of short-term study abroad experiences. (Unpublished Master Thesis, Bowling Green State University, Bowling Green, $\mathrm{OH}$.

Bowling Green State University. $\left(2013^{\mathrm{a}}\right)$. Bowling Green State University's Strategic Plan. Retrieved from http://www.bgsu.edu/strategicplanning/page122224.html

Bowling Green State University. (2013 $\left.{ }^{\mathrm{b}}\right)$. President's State of the University Address. Retrieved from http://www.bgsu.edu/offices/president/state_of the_university_1.html

Creswell, J. (2008). Research design: Qualitative, quantitative, and mixed methods approaches ( $3^{\text {rd }}$ ed.). Thousand Oaks, CA: Sage Publications. (Chapter 1). Retrieved February 12, 2013, from www.sagepub.com/upm-data/10981Chapter_1.pdf

Friedman, T.L. (2006). The World Is Flat: A Brief History of the Twenty-First Century. New York: Farrar, Straus, and Giroux.

Gay, G. (2002). Preparing for culturally responsive teaching. Journal of Teacher Education, 53, 106-116.

Malewski, E., Sharma, S. \& Phillion, J. (2012). How international field experiences promote cross-cultural awareness in pre-service teachers through experiential learning: Findings from a six-year collective case study. Teachers College Record, 114 (8), 1-44.

New, R. S. (2001). Italian Early Care and Education: The Social Construct of Policies, Programs and Practices. In Phi Delta Kappan 226- 236.

Ortiz, J., \& Tajes, M. (2010). Assessing study abroad programs: Applications of the "SLEPT" framework through learning communities. The Journal of General Education, 59 (1), 17-41.

Perry, L., Stoner, L., \& Tarrant, M. (2013). More than a vacation: Short-Term study abroad as a critically reflective, transformative learning experience. Creative Education, 3 (5), 679-683.

Stearns, P. N. (2009). Educating global citizens in colleges and universities: Challenges and opportunities. New York: Routledge.

Tarrant, M.A. (2010). A conceptual framework for exploring the role of studies abroad in nurturing global citizenship. Journal of Studies in International Education, 14, 433-451.

Wooldridge, D.G., Peet, S., \& Sturm, M. (in press). Preparing Pre-Service Teachers for A Global Society: A Short-Term Study Abroad Program in Italy The One 
Voice International Collection of Scholarly Works 2014. Philadelphia, PA.

United Nations. (2013). International Migration Report 2013. New York: Author. Bowman, M., Debray, S. K., and Peterson, L. L. 1993. Reasoning about naming systems. ACM Trans. Program. Lang. Syst. 15, 5 (Nov. 1993), 795-825. DOI= http://doi.acm.org/10.1145/161468.16147.

\section{Appendix A: Brief Overview of the School-Based Experiences in Italy}

During the study abroad experience, students experienced five different school-based sites, including the Mama Mara Infant School, the Instituto Cannossiano Scoula Audiofonetica, the PinAc Children's Art Museum, Reggio Children, and an English Language Learning Workshop. All five experiences provided students with different educational philosophies and techniques of teaching. These experiences were selected to prepare culturally responsive teachers. Experiences were selected to promote pre-service teachers' intercultural development and provide unique opportunities for these students to consider the ways culture influences teaching and learning. The following are summaries of the five learning experience sites and what students observed at each site.

\section{Mama Mara Infant School}

Mama Mara Infant School is located in San Polo D'Enza, Italy. The school is based on the intergenerational concept of learning across the lifespan and inclusion. The curriculum is grounded in the integration of the arts into learning. Students observed learning experiences based on form, function, fibers, textures, everyday objects, weaving, and the influence of modern artists. Themes emerged from student reflections such as the importance of art, inclusion, lifespan development, and collaboration. Students noted:

- The best part of this school was seeing all the artwork and the focus on inclusion. It was also challenging to experience the language barrier with the children.

- We observed many opportunities for implementing elements of inclusion.

- Integrated working with people who are old, young and disabilities.

- Everything was amazing. I felt touched to be there. It was a blessing to witness that collaborative environment.

\section{Instituto Cannossiano Scoula Audiofonetica}

The Instituto Cannossiano Scoula Audiofonetica is a school located in Brescia, Italy where children with hearing disabilities are included in the classroom setting. All children are exposed to techniques using sound and movement to teach math, reading, music, and the like. Themes emerged from student reflections such as the importance of inclusion, sound, movement, 
collaboration, and the passion for teaching/learning:

- The demonstration laboratory with the drums and circles was the best part of the day. It was so cool to watch. I thought it was interesting how they were able to teach students through vibrations.

- Best part was seeing the laboratories and watching individuals and groups working together.

- Very interesting how music, art and math are taught together. Very good.

- Seeing the classrooms, especially the math demonstration. Also, the very passionate teachers.

\section{PinAc Children's Art Museum}

The PinAc Children's Art Museum is located in Rezzato, Italy. PinAc Children's Art Museum provides value added experiences for local pre-schools and schools through field trips and experiences for children with local artists in residence. Themes emerged from student reflections such as the importance of creativity, using all senses, movement, and the passion for teaching/learning:

- The best part of the visit was observing the teacher/artist; she was awesome and knew so much even without training to be a teacher.

- I enjoyed watching the children make their own sounds using their bodies. This was a creative way for them to learn and they seemed to enjoy it.

- Very interesting children's museum. The workshop was awesome. I liked how the children made music.

\section{Reggio Children}

Reggio Children is located in Reggio Emilia, Italy at the Loris Malaguzzi International Center. This Center promotes the Reggio Emilia Approach, which is an educational philosophy focused on preschool and primary education. This approach provides children learning opportunities where they can explore and discover based on the interests of the children through a self-guided curriculum. Themes emerged from student reflections such as the importance of problem solving, asking the right questions, using all senses and creating the right learning environment. Students noted:

- The presentation was very informative. We got to participate in the activities. We walked through the courses and had a great time.

- The light show was really interesting. The process encourages children to solve problems.

- The light show was awesome; it gave me good ideas for the future. 
- The Ray of Light Power point was the best part of the day. It gave me some great activities in the light area for senses.

English Language Learning Workshop at La Scoula Publishing Company

The English Language Learning Workshop was sponsored by La Scoula Publishing Company located in Brescia, Italy. Linda Edwards was the presenter. Students were exposed to learning activities in which they were the language learners. Themes emerged from student reflections such as the importance of passion in teaching, creating the right environment, use of various engaging teaching strategies, and always focus on the learner. Students reflected:

- Linda is a fantastic teacher! I absolutely loved our workshop with her. Her energy rubbed off on us and she got us motivated to participate in interactive strategies not just worksheets.

- Actually doing activities from the perspective of language learners. She encouraged us to focus on multiple kinds of application; it was fun and she had a lot of enthusiasm. 
